\title{
Law enforcement and cardiovascular risk: Findings of a cross-sectional study from Rural Karnataka
}

\author{
Carolin Elizabeth George ${ }^{1}$, Norman Gift ${ }^{2}$, Devashri Mukherjee ${ }^{3}$, Tatarao Maddipati ${ }^{4}$ \\ ${ }^{1}$ Consultant, ${ }^{2}$ Professor and Head, ${ }^{3}$ Research Consultant, ${ }^{4}$ Statistician, Department of Community Health and Family \\ Medicine, Bangalore Baptist Hospital, Bangalore,Karnataka, India
}

Background: Police personnel experience job-related factors that put them at risk of heart disease. Close encounter with difficult situations and unpredictability of working hours pose them with high stress which can increase the chance of heart disease. Aims and Objective: The current study aims to find out the prevalence of individual and aggregated cardiovascular disease (CVD) risk factors and a10 year risk prediction of a fatal or non-fatal cardiac events using the Framingham risk score. Materials and Methods: A cross sectional study was conducted among 60 police personnel of Devanahalli Taluk in Bangalore rural district. The study comprised a pre tested semi structured questionnaire; body mass index, waist circumference, waist hip ratio systolic and diastolic blood pressure measurements, and random plasma glucose estimation. Pearson's correlation coefficients were calculated for Framingham risk score with individual CVD risk factors. Multivariate logistic regression was done to measure the association of CVD risk factors with Framingham risk score. Results: The prevalence of aggregated cardiovascular risk was high, $85 \%$ of them had a combination of 2 or more risk factors. Greater age (> 50 years), smoking, waist circumference, waist hip ratio and presence of hypertension were significantly associated with high 10 year CVD risk categories. Age and systolic blood pressure showed a significant positive correlation with CVD risk. Conclusion: An alarming $40 \%$ of the police personnel had a high risk of a fatal or non-fatal cardiac event in the next 10 years. This warrants the need for regular CVD risk factor screening and targeted health education programs along with lifestyle modification counselling.

Key words: Cardiovascular risk factors, Police personnel, Framingham risk score
Access this article online

Website:

http://nepjol.info/index.php/AJMS

DOI: 10.3126/ajms.v8i3.16582

E-ISSN: 2091-0576

P-ISSN: $2467-9100$

\section{INTRODUCTION}

Police personnel constitute a special occupational group with exposure to violence at work, which directly and indirectly affects their health. ${ }^{1,2}$

It has been reported by researchers that due to enormous stress, police officers suffer from different physiological disorders, such as gastrointestinal, insomnia, psychological disorders, family dysfunction ${ }^{1,3-9}$ and cardiovascular disorders ${ }^{10,11}$ than the general population. The objective of the study was to estimate the burden of individual and aggregated CVD risk factors and predict the 10 year risk of fatal and non-fatal cardiovascular event in this population using Framingham risk score.

\section{MATERIALS AND METHODS}

This is a cross sectional study done in Devanahalli Taluk in Bangalore Rural district. Devanahalli Taluk is divided into three police circles, Vishwanathapura, Devanahalli and Vijayapura. These three police stations were conveniently sampled for study. Each circle has a police station manned 
by an Inspector and many sub inspectors. There were 112 police personnel working in these three circles. Sixty police personnel participated in this study.

The screening team consisted of doctors, nurses and health workers. The participants were interviewed using a semi structured questionnaire which contained basic demographic details and information on history of hypertension, diabetes or heart disease, dietary habits, physical activity and personal habits such as smoking and alcohol intake.

A diet consisting of three servings of vegetables and 2 servings of fruits per day and consumption of junk foods less than twice a week was considered as healthy diet. Half an hour of brisk walking, jogging or swimming or aerobic exercise at least 5 times a week was considered as adequate physical activity. ${ }^{12}$

A general examination was done followed by anthropometric measurements.Standing body height was measured with a commercial stadiometer in $\mathrm{cm}$ (to the nearest $0.5 \mathrm{~cm}$ ). A digital scale, with an accuracy of $\pm 100 \mathrm{~g}$, was used to measure body weight and was recorded in $\mathrm{kg}$. The body mass index (BMI) was calculated using the formula weight $(\mathrm{kg}) /$ height $\left(\mathrm{m}^{2}\right) \cdot{ }^{13}$ Normal cut off values for BMI was $23 \mathrm{~kg} / \mathrm{m}^{2}$ for both the genders. Waist circumference was measured in a horizontal plane, midway between the inferior margin of the ribs and the superior border of the iliac crest, using a standard inelastic measuring tape. Waist to Hip ratio was calculated by measuring the waist and the hip (at the widest diameter of the buttocks), and then dividing the waist measurement by the hip measurement. ${ }^{13}$ Measurements were taken twice and the mean was taken in all cases.Cutoff values for waist circumference were 85 and $80 \mathrm{~cm}$ for men and women, respectively ${ }^{14}$ the corresponding waist hip ratios were 0.90 and 0.81 respectively. ${ }^{15}$

Blood pressure (BP) was recorded by a trained physicians in the sitting position in the right arm with a mercury sphygmomanometer (Diamond Deluxe BP apparatus, Pune, India). Three readings were taken 5 minutes apart and the mean of the two lower readings was taken as final BP. Hypertension was diagnosed based on a past medical history or if the BP was $>140 / 90 \mathrm{~mm} \mathrm{Hg}$ as per JNC 7 criteria. ${ }^{16}$ Diabetes screening was done using Glucometer. A value more than $200 \mathrm{mg} / \mathrm{dl}$ was considered as diabetes.

After completion of the risk assessment, the risk profile was discussed with the individual and counseling on risk minimisation was given, if found to have modifiable risk factors. Follow up counseling and management of treatable conditions were facilitated by the research team.

Classification of CVD Risk Profile of the Participants For studying the burden of CVD risk, two different methods were used. Firstly, the individual and the aggregated risk factors were studied. Secondly, the Framingham risk score (probability of 10-year risk of a fatal or nonfatal major cardiovascular event i.e., myocardial infarction or stroke) a was calculated using toage, sex, and systolicblood pressure, treatment of hypertension, smoking status, diabetes mellitus and BMI. The risk levelwasfurtherclassified as $<10 \%, 10 \%-<20 \%, 20 \%-<30 \%, 30 \%-<40 \%$ and $40 \%$ or more. For analysis theoutcome in the current study was categorised in two groups: high risk (>10\% risk) and low risk $(<10 \%$ risk $) .{ }^{17}$

\section{Statistical Analysis}

Statistical analysis was done using the SPSS 16.0 program (Statistical Package for Social Sciences; SPSS Inc., Chicago, IL, USA) for Windows 7. Mean and standard deviation was calculated for continuous variables and frequencies were calculated for categorical variables. Chi square tests and correlation test was done to determine the association between categorical and continuous variables respectively.

The distribution of individual and the aggregated CVD risk factors were assessed. Pearson's correlation coefficients were calculated for Framingham risk score with study variables like age, BMI, SBP, waist hip ratio, diabetes and waist circumference.

Multivariate logistic regression was done to measure the association of cardiovascular risk factors (age, gender, education, smoking, alcohol consumption, presence of diabetes, hypertension, waist-hip ratio, BMI etc) with high Framingham risk score (score more than 10). Significance level was defined as $P<0.05$.

\section{RESULTS}

Among the 82 police personnel working in the area, 60 participated in the study giving a response rate of $73.1 \%$. Most of them (96.7\%) were constables. Their ages ranged from 23 to 60 years with a mean of 42.63 years. All belonged to Hindu religion and majority $(91.7 \%)$ were males. Mean BMI of the participants was $25.17 \mathrm{~kg} / \mathrm{m}^{2}$ and waist circumference was $86.75 \mathrm{~cm}$.

Table 1 shows the distribution of various risk factors among the study population. More than three forth $(73.3 \%)$ of the studied population had a BMI greater 


\begin{tabular}{|c|c|c|}
\hline $\mathrm{N}=60$ & No. & $\%$ \\
\hline \multicolumn{3}{|l|}{ Physiological Risk factors } \\
\hline Hypertension & 5 & 8.3 \\
\hline Pre hypertension & 9 & 15.0 \\
\hline Impaired glucose $(180-200 \mathrm{mg} / \mathrm{dl})$ & 2 & 3.3 \\
\hline Diabetes & 3 & 5.0 \\
\hline Family History (HTN/DM or heart disease) & 6 & 10.0 \\
\hline $\mathrm{BMI}(>23)$ & 44 & 73.3 \\
\hline Waist circumference & 38 & 63.3 \\
\hline Waist hip ratio & 34 & 56.7 \\
\hline \multicolumn{3}{|l|}{ Behavioural risk factors } \\
\hline $\begin{array}{l}\text { Inadequate vegetable consumption (Less } \\
\text { than } 3 \text { servings a day) }\end{array}$ & 24 & 40.0 \\
\hline $\begin{array}{l}\text { Inadequate fruit consumption (Less than } \\
2 \text { servings a day) }\end{array}$ & 43 & 71.7 \\
\hline Junk food (More than two times a week) & 22 & 36.66 \\
\hline Unhealthy diet & 51 & 85.0 \\
\hline Inadequate physical activity & 29 & 48.3 \\
\hline Alcohol & 12 & 20.0 \\
\hline Smoking & 9 & 15.0 \\
\hline \multicolumn{3}{|l|}{ Framingham CVD risk } \\
\hline CVD high risk (More than $10 \%$ risk) & 24 & 40.0 \\
\hline
\end{tabular}

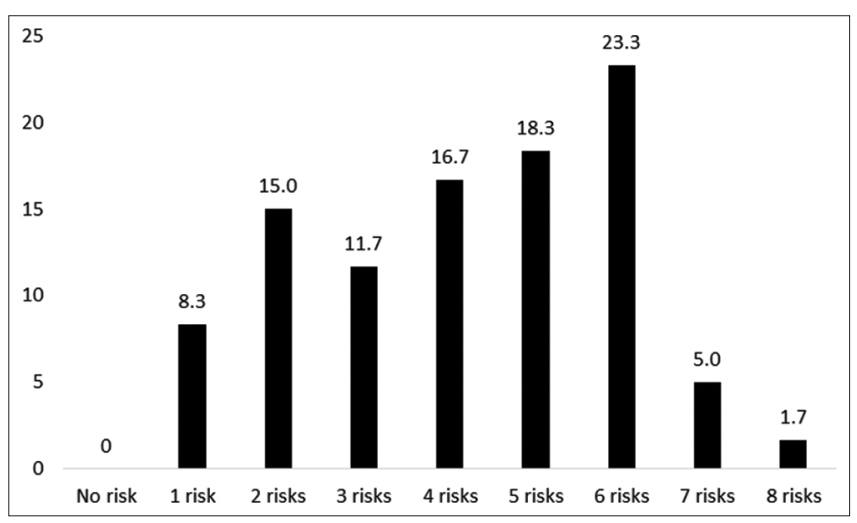

Figure 1: Aggregated risk factor burden*(in percentages) $(n=60)$ [* Hypertension, Diabetes, Smoking, Alcohol, Risk BMI, unhealthy diet, physical inactivity waist circumference and waist hip ratio were taken as risk factors]

than 23 and more than half (63.3\%) had risk waist circumference. Five percent of the study population were diabetic. Majority (85\%) of them consumed unhealthy diet. Almost half $(48.5 \%)$ had inadequate physical activity. Prevalence of smoking and alcohol was 15 and $20 \%$ respectively.

Figure 1 depicts the presence of the aggregated risk burden in the population by classifying on the basis of number of risk factors present, single or combination. Not a single participant was found without any behavioural or physiological risk factor for CVD. An alarming $85 \%$ had a combination of 2 or more risk factors (hypertension, diabetes, smoking, alcohol, risk BMI, unhealthy diet, physical inactivity, risk waist circumference and risk waist hip ratio).

High Framingham risk score (FRS) was present in 40\% of the police personnel. Logistic regression showed that greaterage $(>50$ years), education level, smoking, waist circumference, waist hip ratio and presence of hypertension were independently associated high Framingham CVD risk score (Table 2). Gender, unhealthy diet, alcohol consumption, diabetes, physical inactivity and risk BMI were not associated with high FRS.

Pearson's correlation was done for age, waist circumference, waist hip ratio, systolic blood pressure, random blood sugar and BMI with Framingham risk score. All except BMI showed a positive and significant correlation with 10 year CVD risk and among them age had a stronger correlation. Random blood sugar showed a moderate but significant correlation with 10 year CVD risk $(r=0.401$, $\mathrm{p}=0.001$ (Figure 2). Correlation between BMI and FRS was not significant $(\mathrm{r}=0.15, \mathrm{p}=0.23)$.

\section{DISCUSSION}

The present study revealed a high prevalence of CVD risk factors especially high BMI, waist circumference and overall Framingham score. However the prevalence of hypertension and diabetes were low compared to other studies conducted among police in India. This difference may be due to the fact that the study was conducted in a rural area.

The prevalence of diabetes varied in studies done in different parts of India among general population, 13.5\% in Chennai, $12.4 \%$ in Bangalore, and 16.6\% in Hyderabad (as per National Urban Diabetes Survey). ${ }^{18}$ However the studies conducted by Tharkar et $\mathrm{al}^{19}$ from Chennai and Ramakrishnan et $\mathrm{al}^{20}$ from Puducherry reported a higher prevalence of diabetes among police personnel, 32\% and $33.6 \%$ respectively compared to the present study $(8.3 \%)$.

In the present study, the prevalence of hypertension was $8.3 \%$ as compared to $30.5 \%$ and $58.5 \%$ in the studies conducted by Ramakrishnan et $\mathrm{al}^{20}$ and Shabana et $\mathrm{al}^{19}$ respectively. The higher prevalence may be due to the difference in age distribution; our study comparatively had younger police personnel than the other studies. A study done in Nagpur reported that younger policemen were almost free of hypertension and older police had a prevalence as high as $37 \% .^{21}$ Shabana et al had taken a lower cut off of 130/85 mm of $\mathrm{Hg}$ for hypertension which may explain this difference. 


\begin{tabular}{|c|c|c|c|c|c|}
\hline \multirow[t]{2}{*}{ Variable $(n=60)$} & \multirow{2}{*}{$\begin{array}{c}\text { Low risk of CVD } \\
(\text { score }<10)\end{array}$} & \multirow{2}{*}{$\begin{array}{c}\text { High-risk of CVD } \\
\text { (score }>10)\end{array}$} & \multirow[t]{2}{*}{ Total } & \multirow[t]{2}{*}{ Chi-square value } & \multirow[t]{2}{*}{ P-value } \\
\hline & & & & & \\
\hline \multicolumn{6}{|l|}{ Age } \\
\hline$<50$ & 32 & 4 & 36 & 31.296 & 0.00 \\
\hline$>50$ & 4 & 20 & 24 & & \\
\hline \multicolumn{6}{|l|}{ Sex } \\
\hline $\mathrm{F}$ & 5 & 0 & 5 & 3.636 & 0.077 \\
\hline M & 31 & 24 & 55 & & \\
\hline \multicolumn{6}{|l|}{ Educational Status } \\
\hline High school to PUC & 19 & 21 & 40 & 7.813 & 0.006 \\
\hline Degree and above & 17 & 3 & 20 & & \\
\hline \multicolumn{6}{|l|}{ Smoking } \\
\hline No & 36 & 15 & 51 & 12.5 & 0.00 \\
\hline Yes & 0 & 9 & 9 & & \\
\hline \multicolumn{6}{|l|}{ Alcohol } \\
\hline No & 31 & 17 & 48 & 2.101 & 0.147 \\
\hline Yes & 5 & 7 & 12 & & \\
\hline \multicolumn{6}{|l|}{ Diet } \\
\hline Healthy & 4 & 5 & 9 & 1.068 & 0.462 \\
\hline Unhealthy & 32 & 19 & 51 & & \\
\hline \multicolumn{6}{|l|}{ Physical activity } \\
\hline Adequate & 18 & 11 & 29 & 0.1 & 0.752 \\
\hline Inadequate & 18 & 13 & 31 & & \\
\hline \multicolumn{6}{|l|}{ BMI Risk } \\
\hline No & 12 & 4 & 16 & 2.045 & 0.153 \\
\hline Yes & 24 & 20 & 44 & & \\
\hline \multicolumn{6}{|l|}{ Waist Circumference } \\
\hline No risk & 17 & 5 & 22 & 4.318 & 0.038 \\
\hline Risk & 19 & 19 & 38 & & \\
\hline \multicolumn{6}{|l|}{$\begin{array}{l}\text { Waist by Hip ratio } \\
\text { risk }\end{array}$} \\
\hline No risk & 21 & 5 & 26 & 8.247 & 0.004 \\
\hline Risk & 15 & 19 & 34 & & \\
\hline \multicolumn{6}{|l|}{ Hypertension } \\
\hline No & 34 & 21 & 55 & 9.814 & 0.004 \\
\hline Yes & 2 & 3 & 5 & & \\
\hline \multicolumn{6}{|l|}{ Diabetes } \\
\hline No & 35 & 20 & 55 & 3.636 & 0.147 \\
\hline Yes & 1 & 4 & 5 & & \\
\hline
\end{tabular}

The prevalence of risk BMI in this study was consistent $(73.3 \%)$ as compared to Puducherry study $(75.8 \%) .{ }^{20}$ the prevalence was higher than Chennai study $(62.9 \%)^{19}$ and Kerala study $(66 \%){ }^{2}$

Most of the police personnel $(63.3 \%)$ had a waist circumference $>85 \mathrm{~cm}$ as compared to $71.5 \%$ and $65.1 \%$ (Waist Circumference $>90 \mathrm{~cm}$ ) reported by Ramakrishnan et $\mathrm{al}^{20}$ and Shabana et $\mathrm{al}^{19}$ respectively.

An alarming 40\% had a high Framingham risk score and all of them had at least one CVD risk factor. Older age, smoking, presence of hypertension and larger waist circumference and waist-hip ratio were found significantly associated with high FRS. However there are no studies to compare these results.

\section{Limitations}

Stress assessment and an age and gender matched general population for comparison would have added value to the study.

\section{CONCLUSION}

Police personnel constitute a special occupational group that is prone to increased CVD risk.It is unfortunate that a group selected for remarkable physical fitness at the entry stage fail to maintain it and succumb to lifestyle diseases that are easily preventable. Similar results from other parts of India and the world calls for attention from policy makers to introduce effective strategies to overcome this problem. Workplace programs to promote the health and 

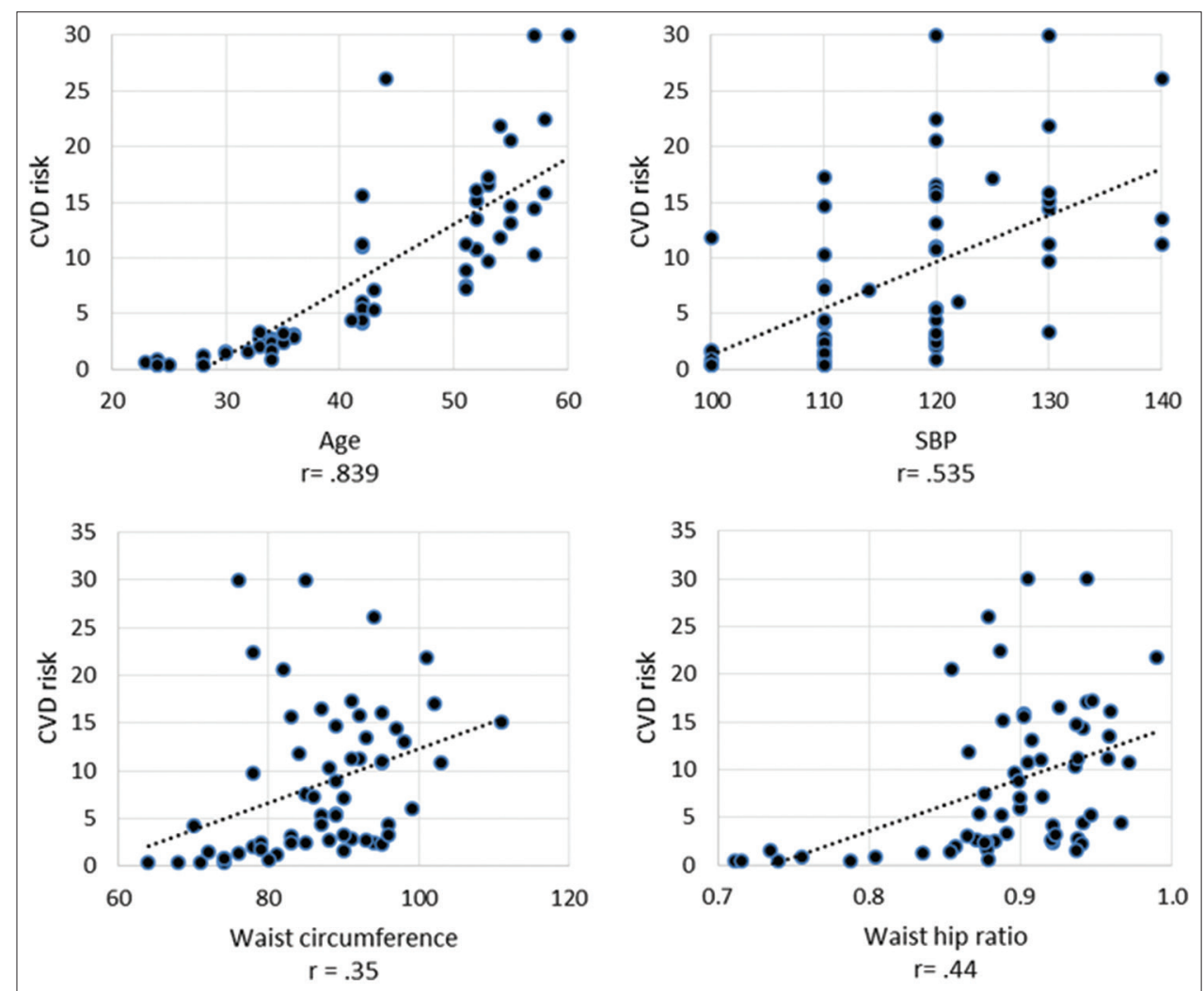

Figure 2: Correlation of CVD risk with other variables

regular screening of police officers for CVD risk factors can be an effective means for reducing cardiovascular risk.

\section{ACKNOWLEDGEMENT}

Saving Hearts team.

\section{REFERENCES}

1. Saha A, Sahu S and Paul G. Evaluation of cardio-vascular risk factor in police officers. International Journal of Pharma and Bio Sciences 2010;1(4):263-271.

2. ThayyilJ, JayakrishnanTT, RajaMand Cherumanalil JM. Metabolic syndrome and other cardiovascular risk factors among police officers. N Am J Med Sci 2012;4(12):630-635.

3. Franke WD, Cox DF, Schultz DP and Anderson DF. Coronary heart disease risk factors in employees of lowa's department of public safety compared to a cohort of the general population. Am $\mathrm{J}$ Ind Med 1997;31(6):733-777.

4. Violanti JM, Mnatsakanova A, Burchfiel CM, Hartley TA and Andrew ME. Police suicide in small departments: A comparative analysis.Int J Emerg Ment Health 2012;14(3):157-162.

5. Gershon RR, Lin S and Li X. Work stress in aging police officers. J Occup Environ Med 2002;44(2):160-167.

6. Liberman A, Best S, Metzler T, Fagan J, Weiss O and Marrnar C. Routine occupational stress and psychological distress in police. Policing: Int J Police Strateg Manag 2002; 25(2):421-439.

7. Neylan TC, Metzler MA, Best SR, Weiss DS, Fagan JA, Liberman A, et al. Critical incident exposure and sleep quality in police officers.Psychosom Med 2002; 64(2):345-352.
8. Mellinger GD, Balter $\mathrm{MB}$ and Uhlenhuth $\mathrm{EH}$. Insomnia and its treatment: Prevalence and correlates.Arch Gen Psychiatry 1985;42(3):225-232.

9. Franke WD and Anderson DF. Relationship between physical activity and risk factors for cardiovascular disease among law enforcement officers. J Occup Med1994;36(10):1127-1132.

10. Blackmore J. Are police allowed to have problems of their own? Police Magazine 1978; 1(3): 47-55.

11. Axelbend $M$ and Vaile J. South Florida's approach to police stress management. Police Stress 1979;1:13-16.

12. Stuart-Shor EM, Berra KA, Kamau MW and Kumanyika SK. Behavioral strategies for cardiovascular risk reduction in diverse and underserved racial/ethnic groups. Circulation 2012; 125(1):171-184.

13. Obesity Prevention Source: Measuring Obesity [online] [Cited 2015 Mar 10]. Available from: URL: http://www.hsph.harvard. edu/obesity-prevention-source/obesity-definition/how-tomeasure-body-fatness

14. Snehalatha $C$, Viswanathan $V$ and Ramachandran A. Cutoff values for normal anthropometric variables in Asian Indian adults. Diabetes Care 2003;26(5):1380-1384.

15. Khader YS, Batieha A, Jaddou H, Batieha Z, El-Khateeb M and Ajlouni K.Anthropometric cutoff values for detecting metabolic abnormalities in Jordanian adults. Diabetes Metab Syndr Obes 2010;3:395-402.

16. Chobanian AV, Bakris GL, Black HR, Cushman WC, Green LA, Izzo JL, et al. Seventh report of the Joint National Committee on Prevention, Detection, Evaluation, and Treatment of High Blood Pressure. Hypertension 2003;42(6):1206-1252.

17. Framingham heart study: Cardiovascular Disease (10-year risk) [online] 2015 [Cited 2015 Mar10]. Available from: URL: www.framinghamheartstudy.org/risk-functions/cardiovasculardisease/10-year-risk.php 
18. Ramachandran A, Snehalatha $C$ and Kapur A. High prevalence of diabetes and impaired glucose tolerance in India: National Urban Diabetes survey. Diabetologia 2001;44:1094-1101.

19. Tharkar S, Kumpatla S, Muthukumaran P and Viswanathan V.High prevalence of metabolicsyndrome and cardiovascular risk among police personnel compared to general population in India. J Assoc Physicians India 2008; 56:845-849.
20. Ramakrishnan J, MajgiSM, PremarajanKC, LakshminarayananS, Thangaraj $S$ and Chinnakali P.High prevalence of cardiovascular risk factors among policemen in Puducherry, South India.J Cardiovasc Dis Res 2013;4(2):112-115.

21. Rastogi P. Diet and High Blood Pressure [Online] 2014 [Cited 2015 Mar10]. Available from: http://www.sajpc.org/vol9/vol9 4/ diet_n_high_bp.htm

\section{Authors Contribution:}

CEG-Concept and design of the study, manuscript preparation, statistically analyzed and interpreted, critical revision of the manuscript;NG- Concept and design of the study, critical revision of manuscript and review of the study; DM- reviewed the literature, helped in preparing first draft of manuscript, collected data; TMcollected data, statistically analyzed and interpreted, helped in preparing first draft of manuscript.

\section{Work attributed to}

Department of Community Health and Family Medicine, Bangalore Baptist Hospital.

Orcid ID:

Dr. Carolin Elizabeth George: (10) http://orcid.org/0000-0001-7086-200X

Dr. Gift Norman: (1) http://orcid.org/0000-0003-0103-5507

Dr. Devashri Mukherjee: (1) http://orcid.org/0000-0001-8364-7915

Mr. Tatarao Maddipati: (iD http://orcid.org/0000-0003-1210-9110 